\title{
Influence of coating on the triamcinolone release of alginate chitosan beads for colonic drug delivery
}

\author{
Nadir Veiga Vier, Ruth Meri Lucinda-Silva* \\ Programa de Mestrado em Ciências Farmacêuticas, Núcleo de Investigações Químico-Farmacêuticas (NIQFAR), Pharmacy Course, \\ University of Vale do Itajaí, Itajaí, Brazil; ${ }^{*}$ Corresponding Author: rlucinda@univali.br
}

Received 9 March 2011; revised 14 May 2011; accepted 15 June 2011.

\begin{abstract}
The aim of this study was to evaluate the effect of coating of alginate-chitosan (AL:CS) beads on the colonic drug delivery. The AL:CS systems containing triamcinolone (TC) were coated with the HPMCP and Eudragit ${ }^{\circledR}$ L100 by immersion and by spraying methods. The drug release profile in simulated colonic medium was determined using $5 \%$ human fecal content suspension in $0.01 \mathrm{~N}$ buffer solution, $\mathrm{pH}$ 6.8. The systems coated with HPMCP showed a lower rate of drug delivery in simulated enteric medium. The delivery profile in simulated colonic medium followed zero-order kinetic. The coated systems provided a promising drug-delivery profile for application in colonic drug delivery.
\end{abstract}

Keywords: Alginate; Beads; Chitosan; Colon-Specific Drug Delivery; Triamcinolone

\section{INTRODUCTION}

Colon-specific drug delivery has attracted the attention of many researchers interested in the treatment of diseases of that specific location, such as ulcerative colitis and Crohn's disease, in its potential as a method of protein and peptide delivery, and in the treatment of circadian diseases, such as rheumatoid arthritis and bronchial asthma [1]. The colon is considered to be an ideal environment for protein and peptide drug absorption, due to the low diversity and activity of digestive enzymes and to its near neutral $\mathrm{pH}[2,3]$.

Colon-specific systems, whose delivery mechanism is the colonic microflora, can be developed using polysaccharides [4]. The polysaccharides remain undigested in the stomach and small intestine, but are degraded by the anaerobic microflora present in the colon. The use of polysaccharides in the development of drug-delivery systems is based on their abundance, as they are very common, cheap, biodegradable, stable and available in a wide variety of structures, with, consequently, a wide variety of physical and chemical properties [5]. Polysaccharides such as chitosan (animal), alginate (marine), pectin (plant), chondroitin sulphate (animal), dextran (microbial) and guar gum (plant) have been used as carriers in colon-specific drug delivery systems [6,7].

Chitosan (CS) is a polymer with a cationic character found in the cell walls of some fungi, and can also obtained from chitin [8], with applications in the fields of cosmetics, biotechnology, microbiology, environmental protection, agriculture, textiles and biomedicine $[9,10]$.

Alginates (AL) are linear water-soluble polysaccharides, which can be extracted from brown algae [8] and are also present in some bacterial species, such as Azotobacter vinelandii and several species of Pseudomonas [11]. They are copolymers consisting of two types of uronate residue, mannuronate $\beta$-D and $\alpha-\mathrm{L}$ guluronate, joined by a glycosidic link $(1,4)[12]$. Because of their various properties, such as immunogenicity, bioadhesion, biocompatibility and biodegradability, the pharmaceutical, food and cosmetics industries, have invested in alginate as carrier of therapeutic systems, including controlled release systems $[6,13]$.

Alginate and chitosan (AL:CS) particles have been used as carriers for the controlled release of proteins and drugs as they are biocompatible, biodegradable and mucoadhesive [14]. The high hydrophilic properties shown by polysaccharides in general are the limiting factor for their individual application in colon-specific drug delivery systems [15]. However, the combination of polysaccharide particles with gastro-resistant polymer coatings can be strategically developed as a tool for controlling drug delivery, maintaining therapeutic action along the gastrointestinal tract (GIT), and enabling drug delivery at the desired target by preventing early swelling and consequent premature drug delivery in the higher GIT [8]. Polymers derived from cellulose, such as hydroxypropyl cellulose phthalate and cellulose acetophthalate, and gastro-resistant film formers like the polymethacrylates, such as methacrylic derivatives of ethacrylic and methyl 
methacrylic polyacids, such as Eudragit ${ }^{\circledR}$, are the most frequently used coatings for this purpose $[16,17]$.

The aim of this study was to determine the effect of two gastro-resistant polymer coatings, hydroxypropyl cellulose phthalate and Eudragit L100 ${ }^{\circledR}$, for the AL:CS beads, using different coating methods, on the colon-specific delivery of triamcinolone, a slightly water-soluble corticosteroid used in the treatment of ulcerative colitis.

\section{MATERIALS AND METHODS}

\subsection{Materials}

Chitosan was purchased from Purifarma ${ }^{\circledR}$ (Brazil), Hydroxypropyl methylcellulose phthalate (HPMCP) was purchased from Sigma ${ }^{\circledR}$ (Brazil), Eudragit ${ }^{\circledR}$ L100 was purchased from Degussa (Germany), sodium alginate was purchased from Vetec ${ }^{\circledR}$ (Brazil) and triamcinolone was purchased from Galena ${ }^{\circledR}$ (Brazil). All other reagents used were of analytical grade.

\subsection{Preparation of $A L: C S$ Systems}

The multiparticulate systems were prepared by the method of complex coacervation/ionotropic gelation. 1\% sodium $\mathrm{AL}$ aqueous dispersion ( $\mathrm{pH}$ 5.5) containing the drug $\left(5 \mathrm{mg} \cdot \mathrm{mL}^{-1}\right)$ was dropped into $0.5 \% \mathrm{CS}$ dispersion in $0.1 \mathrm{~N}$ acetic acid (pH 5.5) containing $1.5 \%$ calcium chloride, using a syringe and needle with a $250 \mu \mathrm{m}$ diameter. The particles were reticulated, separated by filtering, washed with water and freeze-dried.

The AL:CS systems containing TC were coated using 2 different methods: immersion and spray coating. In the immersion coating method (IC), particles were submerged in the polymer dispersions and dried in an oven at $45^{\circ} \mathrm{C}$. The coating materials used were: HPMCP dispersions $(1 \%, 5 \%$ and $7.5 \%$ in acetone:alcohol $1: 1)$ and a $6.8 \mathrm{pH}$ aqueous solution of $1 \%$ Eudragit L100 ${ }^{\circledR}$.

In the spraying coating method (SC), a tablet coating machine was used. The polymer coating dispersion (1\% Eudragit $^{\circledR}$ L100 or $7.5 \%$ HPMCP) was placed under the dried particles, which were coated using a $2 \mathrm{~mL} \cdot \mathrm{min}^{-1}$ spray stream with a pressure of $4 \mathrm{mbar}$ and rotation at 60 $\mathrm{rpm}$. Three layers of the coating were applied in order to increase the system weight by around $10 \%$.

\subsection{Morphological and Granulometric Analyses}

The morphology of the systems was analyzed by scanning electron microscopy (Phillips XL30) and optical microscope (Olympus SZPT). In the SEM analysis, the dried samples were placed on double-sided adhesive tape attached to a metal support, coated with colloidal gold under vacuum and analyzed. In the stereoscopic analysis, the dried particles were placed in glass slides and analyzed using the software Qwin Leica Image Analysis Systems.

Granulometric distribution, area and roundness were assessed by Leica MZ APO stereoscope and Leica Qwin Image Analysis Systems software. Approximately 400 particles were analysed and their size was determined using the diameter according to Feret at $0^{\circ}$.

\subsection{Water Uptake and Swelling Ratio Analysis}

The analysis of water uptake and swelling was evaluated in simulated gastric and intestinal media $(0.1 \mathrm{~N} \mathrm{HCl}$ $\mathrm{pH} 1.5$ and phosphate buffer $\mathrm{pH}$ 7.4). The water uptake by the systems was determined by gravimetry. The particles $(n=10)$ were weighed before and during the $3 \mathrm{~h}$ of contact with the media. The percentage of water uptake $\left(W U\right.$ ) was calculated using Eq.1, where $W_{d}$ and $W_{m}$ are the dry and moist weights of the systems, respectively.

$$
W U(\%)=\left[\left(W_{m}-W_{d}\right) / W_{d}\right] \times 100
$$

The swelling ratio was determined by diameter increase according to the Feret method $\left(0^{\circ}\right)$ using stereoscopic and image analysis software. Swelling capacity was related to the increase in particle diameter, measured individually before and after the contact of the particles with the different media. The swelling ratio was calculated by Eq.2, where $S R$ is the swelling ratio, $d_{1}$ is the diameter after swelling and $d_{0}$ is the diameter before contact with the simulated media.

$$
S R(\%)=\left[\left(d_{1}-d_{0}\right) / d_{0}\right] \times 100
$$

\subsection{Determination of Triamcinolone Content and Entrapment Efficiency}

For determination of drug content, approximately $5 \mathrm{mg}$ of system was placed in contact with $20 \mathrm{~mL}$ of phosphate buffer $50 \mathrm{mM} \mathrm{pH} 7.5$ for $2 \mathrm{~h}$, under stirring. The samples were then filtered and the drug quantified by UV spectrophotometry at $242 \mathrm{~nm}$. Drug content was calculated using Eq.3, where $T E$ is the drug content, $m_{T C}$ is the $T C$ weight quantified in the sample and $m_{\text {syst }}$ is the weight of the system in the sample.

$$
T E(\%)=m_{T C} / m_{s y s t} \times 100
$$

Entrapment efficiency was calculated from drug content and capsule yield using Eq.4, where $E E$ is entrapment efficiency, $T E$ is drug content, $R$ is capsule yield in mass and $M_{\text {TCtotal }}$ is the total mass of drug used in the formulation analyzed.

$$
E E(\%)=(T E \times R) / m_{T C t o t a l}
$$




\subsection{Drug Release Profile}

The assay was performed in a dissolution station using the basket method, under the following conditions: medium volume of $400 \mathrm{~mL}$, agitation speed of $50 \mathrm{rpm}$ and temperature of $37^{\circ} \mathrm{C} \pm 0.5^{\circ} \mathrm{C}$. The release media used were: simulated gastric $(2 \mathrm{~h})$ and enteric $(4 \mathrm{~h})$ juices without enzymes. The drug was quantified by UV spectrophotometry at $242 \mathrm{~nm}$.

The drug release profile in simulated colonic medium $(S C M)$ was determined using 5\% human fecal content suspension in $0.01 \mathrm{~N}$ buffer solution, $\mathrm{pH}$ 6.8. The assay was performed using $300 \mathrm{~mL}$ of medium and agitation of approximately $70 \mathrm{rpm}$ in an anaerobic environment for $24 \mathrm{~h}$. The anaerobic environment was obtained by the insufflation of $\mathrm{CO}_{2}$ produced by the reaction of sodium carbonate $(50 \mathrm{~g})$ with sufficient quantity of $2 \mathrm{M}$ sulfuric acid for saturation of system in a closed environment.

The drug was quantified by HPLC using a reversephase $\mathrm{C} 18$ column, UV detection at $242 \mathrm{~nm}$, temperature at $35^{\circ} \mathrm{C}$, a flow velocity of $1 \mathrm{~mL} \cdot \mathrm{min}^{-1}$ and $0.02 \mathrm{M}$ sodium acetate $(\mathrm{pH} 4.8)$ and acetonitrile (68:32) mobile phase buffer. Samples were quantified after centrifugation and membrane filtration at $0.45 \mu \mathrm{m}$.

\subsection{In Vitro Drug Release Kinetics Analysis}

To study the in vitro drug release kinetics, order zero, first order, Higuchi, Hixon Crowell, Korsmeyer-Peppas and Baker-Lonsdale mathematical models were used. The adequacy of the delivery profiles to the mathematical models was based on the correlation coefficient value [18]. The study was conducted using the software SigmaPlot $^{\circledR}$ version 9.0.

\section{RESULTS AND DISCUSSION}

The uncoated systems containing $T C$ had a greater sphericity compared to the coated systems (Figures 1(a) and (b)). For the coated systems, it was observed that those coated by the immersion method showed a greater uniformity of coating than by the spraying method (Figures 2(a) and (b)). This behaviour is related to the application process and deposition of the polymer dispersion. In the coated particles by immersing was observed a continuous and smooth layer. In the coating by spraying was observed a rough surface probably due to deposition of polymer in the form of fine particles. Another factor that may have influenced the morphology of the particles after the surface was the initial physical state, before or after drying.

The average particle size of coated systems for immersion method foi de 0.76 to $1.03 \mathrm{~mm}$ e de $1.6 \mathrm{~mm}$ for the uncoated systems. These alterations are probably related to the use of desiccative solvents as the vehicles

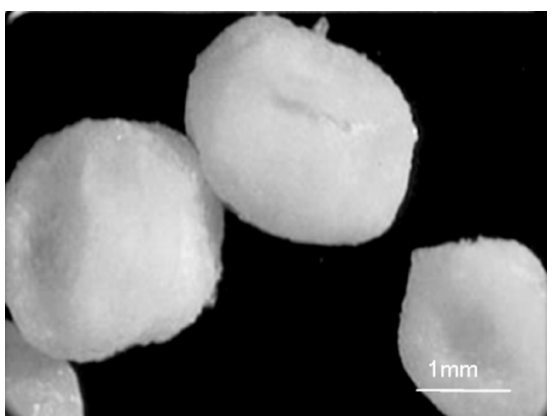

(a)

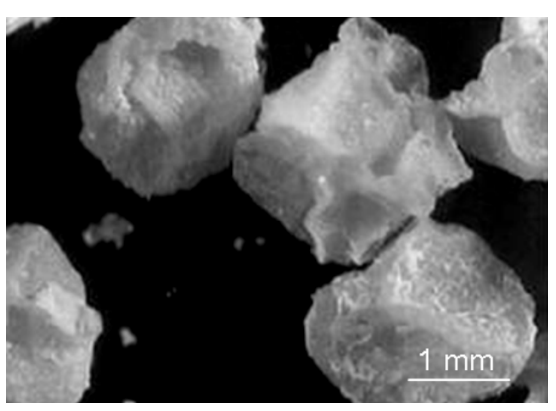

(b)

Figure 1. Photomicrographs of alginate: chitosan systems containing triamcinolone without coating (a) and coated with $1 \%$ Eudragit by the spraying method (b).

of the coating polymers. These solvents may promote the precocious drying of the systems and thus change their morphology and size. The systems coated by the spraying method, 1\% Eudragit $^{\circledR}$ and 7.5\% HPMCP, showed average particle sizes of 1.37 and $1.50 \mathrm{~mm}$.

The formulations showed a encapsulation content of $15.47 \%$ and $17.97 \%$ for particles coated with $7.5 \%$ HPMCP and 1\% Eudragit ${ }^{\circledR}$, respectively. The encapsulation efficiency of the systems was $35.81 \% \pm 9.38 \%$. Being a slightly soluble drug entrapped in a hydrophilic system, a greater encapsulation efficiency was expected. According to Kim et al. [19], the reduction of the matrix and consequent reduction in the level of encapsulation could be caused by the electrostatic interaction between $\mathrm{AL}$ and $\mathrm{CS}$, as systems prepared through the AL-Ca complex, with simultaneous complexation with $\mathrm{CS}$, show a denser form, hindering drug incorporation.

\section{Drug Release in Gastric and Enteric Simulated Media}

In order to evaluate the behaviour during gastrointestinal transit, the AL:CS systems were evaluated for drug delivery in different media. Initially the systems were subjected to simulated gastric medium for 2 hours, followed by enteric medium for $4 \mathrm{~h}$ and finally colonic medium for $24 \mathrm{~h}$. 


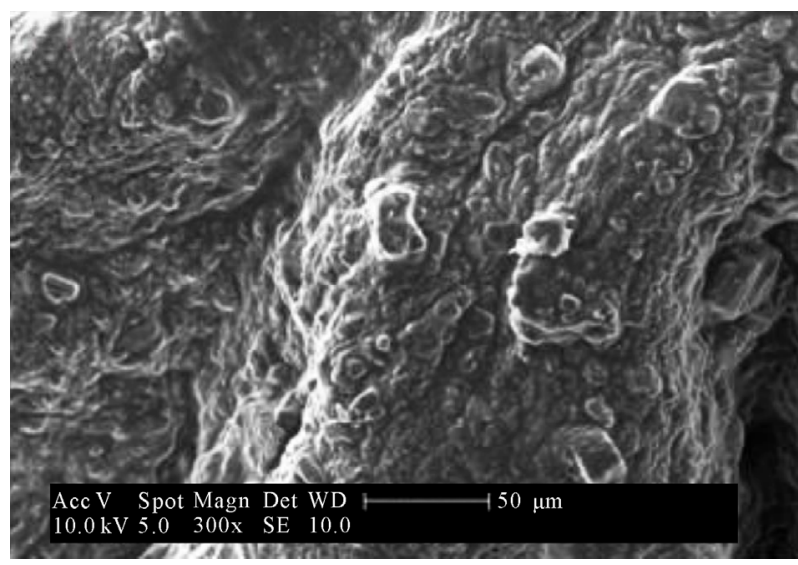

(a)

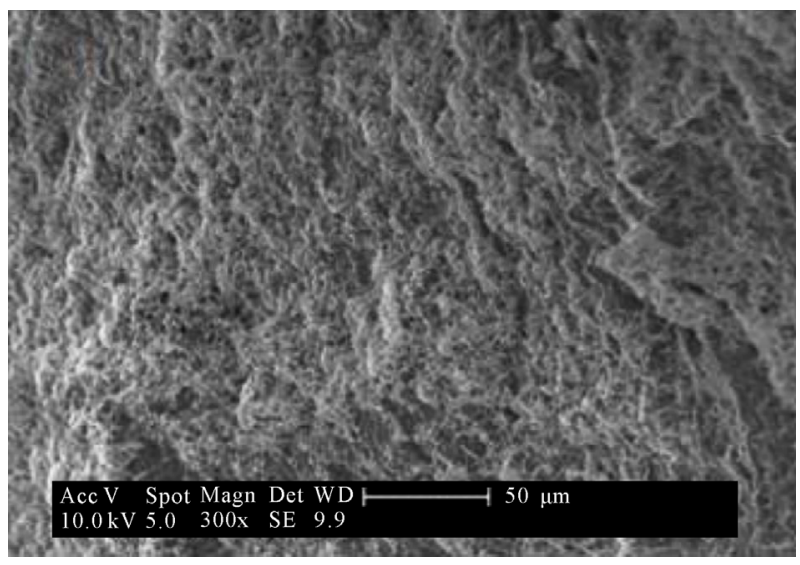

(b)

Figure 2. Photomicrographs of alginate:chitosan systems containing coated with HPMCP by immersion (a) and spraying method (b).

The AL:CS systems were coated with gastro-resistant polymers (HPMCP and Eudragit ${ }^{\circledR}$ ) in order to reduce drug release in the simulated gastric and enteric environments. Polymer coatings for colonic-delivery drugs have been used to protect hydrophilic polymer systems in the higher GIT, particularly by reducing the swelling ratio in the enteric medium.

The coated systems showed a lower release rate in the early hours of testing. In addition to reducing drug re lease in the stomach, the coatings delayed delivery in the enteric medium, as the dissolution and/or swelling of the polymer is necessary for the drug to be delivery.

Figure 3 shows the drug delivery profile of the systems coated with HPMCP in different concentrations, prepared by the immersion and spraying coating methods. It can be seen that drug delivery from the uncoated system was higher after 6 hours compared to the coated systems. The systems coated with 7.5\% HPMCP prepared by the immersion coating method showed a lower ratio of drug release, both in the stomach and enteric

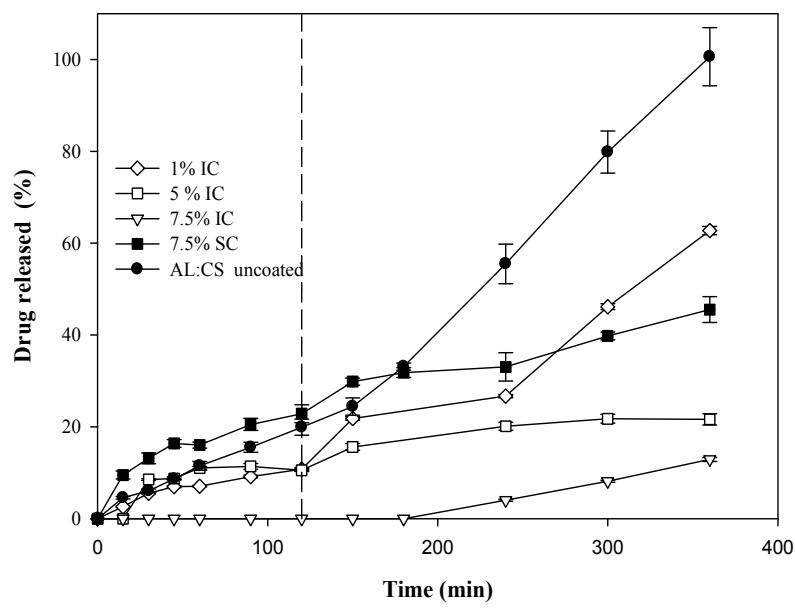

Figure 3. In vitro drug release from the alginate:chitosan systems coated with HPMCP in different concentrations and by different coating methods, immersion (IC) and spraying (SC), in simulated gastric and enteric media.

media, showing total drug retention in the system for the first 180 minutes. This slower drug release is probably due to the polymer concentration and the coating method. By immersion coating method, the increasing the polymer concentration increased the thickness of the coating and, consequently, the dissolution time increased and, the rate of drug released was reduced.

When comparing the release rates for the systems coated with HPMCP and Eudragit ${ }^{\circledR}$, it was observed that the particles coated with HPMCP showed greater control over drug delivery, mainly in gastric simulated environment. This may be related to gastric protection and swelling capacity of HPMCP in pharmaceutical application of drug controlled release. The polymer swelling in enteric environment, form a gelled coating which can control the drug release. Furthermore, the strength of the HPMCP polymer film coating is determined by its molecular weight; that is, the higher the molecular weight, the greater the resistance of the film $[20,21]$ and, conesquently, drug controlled release of the these systems is greater. HPMCP molecular weight values may vary from $78,000-132,000 \mathrm{Da}[21]$. The molecular weight of the HPMCP polymer used in this study was approximately 84,000 Da. Like HPMC, the HPMCP polymer, unlike other polymers, has the ability, after the process of system hydration, to swell and form a gelatinous layer on the surface of the particles, which acts as a barrier to drug release, by controlling water penetration and the speed of release of the drug. The rate of water in gress into the matrix system determines how the drug is released. In very high concentrations, as is the case for particles coated with 7.5\% HPMCP, the linear chains of the polymer become entangled, resulting in a solid gelatinous layer [16]. 
In the comparison of the release profiles of the uncoated system and the systems coated with Eudragit ${ }^{\circledR}$ (by the immersion and spraying coating methods), the coated particles present release rate similar to or greater than the uncoated systems up to 3 hours of proceedings (Figure 4). After $6 \mathrm{~h}$, the particles coated by spraying and immersion method released $50 \%$ and $74 \%$ of drug. For particles coating with Eudragit, the polymer was dissolved in water $(\mathrm{pH} 6,8)$. The need of larger drying time intervals between the applications of spraying coating and the influence of the solvent in the flow of polymer solution can be caused the obtain a coating greater than $10 \%(\mathrm{w} / \mathrm{w})$, initially expected, and a higher retention of the drug incorporated in the matrix, differing from the behaviour observed in matrices coated with PHPMC.

The drug release profile in simulated colonic medium was carried out in human fecal suspension. According to Yang [22], there are four methods for in vitro evaluation of colon-specific delivery systems: conventional simulated enteric environment ( $0.01 \mathrm{M}$ phosphate buffer), use of rat fecal content, use of human fecal content and systems of multi-phase cultures. Fluids with the fecal content of animals, especially rats, have been used to investtigate polysaccharide fermentation. Animal models, such as rats, are available, although these models are relatively expensive for research on metabolic processes mediated by intestinal microorganisms compared to in vitro models. In addition, the animal's digestive physicology differs to that of humans [22].

Figure 5 shows the drug release profiles of the systems in the simulated colonic fluid, after the delivery in simulated acidic and enteric media. The systems coated with HPMCP by immersion coating had delivered about $38 \%$ of the drug after $24 \mathrm{~h}$ in simulated colonic medium.

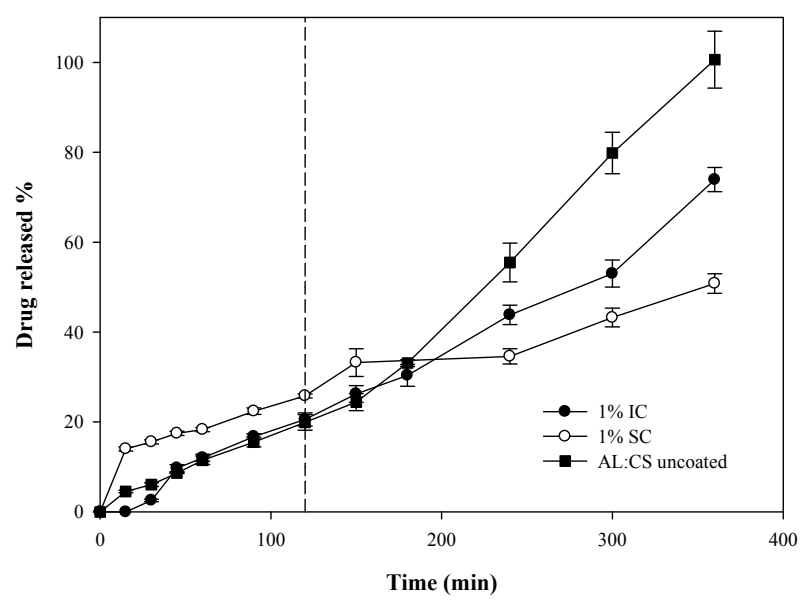

Figure 4. In vitro drug release from the alginate:chitosan systems coated with Eudragit ${ }^{\circledR}$ by different coating methods, immersion (IC) and spraying (SC), in simulated gastric and enteric media.

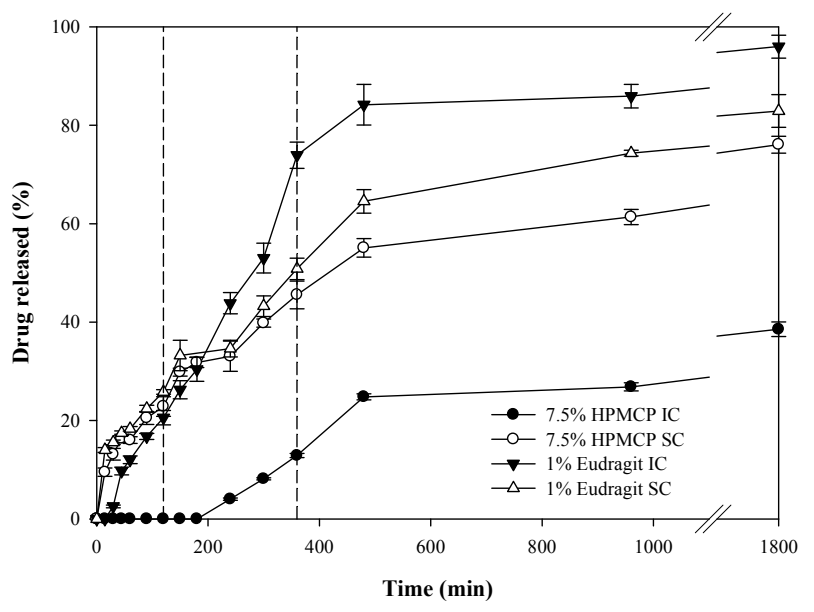

Figure 5. In vitro triamcinolone release from the alginate:chitosan systems coated with different polymers in simulated gastric, enteric e colonic media.

This is probably related to the dissolution of the coating, swelling and erosion of the systems. The systems coated with the same polymer by the spraying method had delivered approximately $76 \%$ of the drug at the end of the assay.

The systems coated with Eudragit ${ }^{\circledR}$ showed a higher rate of drug release by the end of the assay. Greater drug release was observed from the systems coated by the immersion method than by those coated by the spraying method. Although, only the Eudragit ${ }^{\circledR}$ immersion coating system released almost all of the drug in the time period studied, the other systems also showed a constant decline in delivery, with the HPMCP immersion coating batch producing the lowest constant and the lowest amount of drug released after 30 hours of analysis. After evaluating the speed of triamcinolone release and the residence time of the formulation in the colon, the formulation coated with HPMCP was found to be the most promising for the development of colon-specific delivery systems.

Table 1 shows the correlation coefficients of the delivery profiles when applied in different mathematical models in the analysis of the release kinetics. Of the models studied, the release profiles showed higher correlation coefficients for the Korsmeyer-Peppas model. This model is used to examine the release of polymeric dosage forms, when the release mechanism is not well known or when more than one type of apparently unrelated release mechanism may be involved: one due to drug transport (Fickiano transport) and the other related to the swelling and matrix relaxation [16].

For the models derived from the Korsmeyer-Peppas equation, it is the value $n$ that characterizes the drug release mechanism, depending on the geometric shape of the particle [16]. Table 2 shows the $n$ values obtained 
Table 1. Correlation coefficients from the application of different mathematical models for the analyses of the kinetics of alginate: chitosan (AL:CS) systems.

\begin{tabular}{lcccccc}
\hline & \multicolumn{3}{c}{ Correlation coefficient $\left(\mathbf{r}^{2}\right)$} & & \\
\cline { 2 - 7 } & Korsmeyer-Peppas & Baker-Lonsdale & Hixon Crowell & Higuchi & Zero Order & First Order \\
\hline AL:CS & $\mathbf{0 . 9 9 5 9}$ & 0.8002 & 0.9334 & 0.8358 & 0.898 & 0.9123 \\
1\% HPMCP-IC & $\mathbf{0 . 9 8 4 9}$ & 0.8304 & 0.9634 & 0.8492 & 0.8843 & 0.9540 \\
$5 \%$ HPMCP-IC & 0.9643 & $\mathbf{0 . 9 9 8 8}$ & 0.8127 & 0.9641 & 0.9622 & 0.8573 \\
$7.5 \%$ HPMCP-IC & $\mathbf{0 . 9 9 0 5}$ & 0.6478 & 0.8208 & 0.6502 & 0.7252 & 0.8189 \\
$7.5 \%$ HPMCP-SC & 0.9935 & 0.9968 & 0.8233 & $\mathbf{0 . 9 9 8 2}$ & 0.9859 & 0.9189 \\
$1 \%$ Eudragit-IC & $\mathbf{0 . 9 9 4 7}$ & 0.8022 & 0.9779 & 0.9462 & 0.9492 & 0.9691 \\
$1 \%$ Eudragit-SC & $\mathbf{0 . 9 8 5 2}$ & 0.9830 & 0.8693 & 0.9849 & 0.9710 & 0.8906 \\
\hline
\end{tabular}

${ }^{1}$ Immersion coating method; ${ }^{2}$ spraying coating method.

Table 2. $n$ values obtained from the application of drug release profiles to the Korsmeyer-Peppas mathematical model.

\begin{tabular}{lcc}
\hline & n values & $\begin{array}{c}\text { Transport } \\
\text { mechanism }\end{array}$ \\
\hline $1 \% \mathrm{AL}: \mathrm{CS}$ & 1.4569 & Super Case II \\
$1 \% \mathrm{HPMCP} \mathrm{IC}^{1}$ & 1.3886 & Super Case II \\
$5 \% \mathrm{HPMCP} \mathrm{IC}^{1}$ & 0.5153 & Anomalous \\
$7.5 \% \mathrm{HPMCP} \mathrm{IC}^{1}$ & 3.3037 & Super Case II \\
$7.5 \% \mathrm{HPMCP} \mathrm{SC}^{2}$ & 0.5164 & Anomalous \\
$1 \%$ Eudragit IC & 1.1224 & Super Case II \\
$1 \%$ Eudragit SC & 0.4848 & Classic diffusion \\
\hline
\end{tabular}

${ }^{1}$ Immersion coating method; ${ }^{2}$ Spraying coating method.

for the systems. According to the $n$ values, the TC transport mechanism of the systems can be characterized by classic diffusion, anomalous transport and super case II transport, and the mechanism that predominated was super case II, which is characterized by acceleration in solvent penetration in the systems. The speed of solvent diffusion in the matrix is much greater than the swelling, with this being the determining factor in the drug release.

By analyzing the results of the release profile and kinetics, it is possible to better understand the release mechanism as correlated to the swelling results. The systems have a greater water uptake (data not presented) than the swelling ratio, i.e., there is greater absorption and flow of solvent than the increase of polymeric matrix. Systems had higher proportion of swelling in enteric than in acidic media. This behaviour has been observed for systems of chitosan:alginate and chitosan: pectin [23]. The behaviour of reduced swelling and drug release in the simulated gastric medium is related to the ionization of the $\mathrm{AL}$ and $\mathrm{CS}$ polyelectrolytes. In acidic $\mathrm{pH}, \mathrm{CS}$ is protonated with $\mathrm{NH}_{3}^{+}$amino groups and anionic polyelectrolyte, $\mathrm{AL}$, with non-ionized $\mathrm{COOH}^{-}$carboxylic groups and tends to precipitate in the medium. This behaviour can lead to the closure of the structure and, thus, greater control over drug release in acidic medium. The limitation of AL ionization in acid medium, which could lead to its insolubility, probably influenced the release profile behaviour of the coated and uncoated systems.

Coated systems were not eroded in simulate enteric media promoting the controlled release by mechanisms of diffusion and swelling. The systems coated by the HPMCP immersion coating method had a lower swelling ratio compared to the systems coated by the spray coating method (Table 3), probably due to the greater uniformity of the coating, so drug diffusion rates in these systems tends to be lower.

In summary, the different coating methods had an influence on the uniformity of the coating and the roughness of the particles. Swelling behaviour, water uptake and drug release were $\mathrm{pH}$ dependent. There was a lower degree of swelling and release in simulated gastric medium than in simulated enteric medium. Drug release occurred at a slower rate in simulated colonic medium than in simulated gastric and enteric media. All batches showed a constant decline in release, with the HPMCP immersion coating system showing the lowest constant and the lowest amount of drug released after 30 hours of analysis. The Korsmeyer-Peppas model was the most appropriate model for representing the TC delivery profiles of the systems, whose transport mechanism can be characterized by classic diffusion, anomalous transport 
Table 3. Swelling ratio of the alginate:chitosan beads coated with HPMCP and Eudragit ${ }^{\circledR}$ by immersion and spray coating method, after $180 \mathrm{~min}$ in simulate gastric e enteric media.

\begin{tabular}{lcc}
\hline & \multicolumn{2}{c}{ Swelling (\%) } \\
\cline { 2 - 3 } & Gastric $^{\mathbf{1}}$ & Enteric $^{\mathbf{2}}$ \\
\hline $1 \% \mathrm{HPMCP} \mathrm{IC}^{3}$ & $13.04(5.95)$ & $145.90(17.71)$ \\
$5 \% \mathrm{HPMCP} \mathrm{IC}^{3}$ & $8.69(5.02)$ & $128.12(10.19)$ \\
$7.5 \% \mathrm{HPMCP} \mathrm{IC}^{3}$ & $-10.38(1.97)$ & $50.77(6.43)$ \\
$7.5 \% \mathrm{HPMCP} \mathrm{SC}^{4}$ & $23.33(2.88)$ & $104.36(10.80)$ \\
$1 \%$ Eudragit $^{\circledR} \mathrm{IC}^{3}$ & $52.60(8.93)$ & $163.02(4.74)$ \\
$1 \%$ Eudragit $^{\circledR} \mathrm{SC}^{4}$ & $25.00(4.57)$ & $195.02(5.77)$ \\
\hline
\end{tabular}

${ }^{1}$ Mean \pm standard deviation. $\mathrm{n}=5 ;{ }^{2}$ Simulate gastric and enteric media; ${ }^{3} \mathrm{IC}$ immersion coating method. ${ }^{4} \mathrm{SC}$ - spray coating method.

and super case II transport. From the analysis of all the results obtained in this study, in can be concluded that AL:CS multiparticulate systems coated with gastro-resistant polymers represent a promising strategy for therapeutic systems requiring colonic drug delivery.

\section{ACKNOWLEDGEMENTS}

This work was supported by grants from ProPPEC/UNIVALI and FAPESC, Brazil.

\section{REFERENCES}

[1] Liu, H., Wang, C., Gao, Q., Liu, X. and Tong, Z. (2007) Fabrication of novel core-shell hybrid alginate hydrogel beads. International Journal of Pharmaceutics, 351, 104-112. doi:10.1016/j.ijpharm.2007.09.019

[2] Ibekwe, V.C., Fadda, H.M., Parsons, G.E. and Basit, A.W. (2006) A comparative in vitro assessment of the drug release performance of $\mathrm{pH}$-responsive polymers for ileocolonic delivery. International Journal of Pharmaceutics, 308, 52-60. doi:10.1016/j.ijpharm.2005.10.038

[3] Orlu, M., Cevher, E. and Araman, A. (2006) Design and evaluation of colon specific drug delivery system containing flurbiprofen microsponges. International Journal of Pharmaceutics, 318, 103-117. doi:10.1016/j.ijpharm.2006.03.025

[4] Ghaffari, A., Avadi, M.R., Moghimi, H.R., Oskoui, M., Bayati, K. and Rafiee-Tehrani, M. (2008) Mechanistic analysis of drug release from theophylline pellets coated by films containing pectin, chitosan and Eudragit RS. Drug Development and Industrial Pharmacy, 34, 390402. doi: $10.1080 / 03639040701662453$

[5] Vandamme, F.T.H., Lenourry, A., Charrueau, C. and Chaumeil, J.C. (2002) The use polysaccharides to target drugs to the colon. Carbohydrate Polymers, 48, 219-231. doi:10.1016/S0144-8617(01)00263-6

[6] Bajpai, S.K. and Tankhiwale, R. (2006) Swelling behavior of barium ions7crosslinked biopolymeric sodium alginate-carboxymethyl guar gum blend beads. Reactive \&
Functional Polymers, 66, 645-658.

doi:10.1016/j.reactfunctpolym.2005.10.017

[7] Mundargi, R.C., Patil, S.A., Agnihotri, S.A. and Aminabhavi, T.M. (2007) Development of polysaccharidebased colon targeted drug delivery systems for the treatment of amoebiasis. Drug Development and Industrial Pharmacy, 33, 255-264.

doi:10.1080/03639040600897127

[8] George, M. and Abraham, E.T. (2006) Polyionic hydrocolloids for the intestinal delivery of protein drugs: Alginate and chitosan-A review. Journal of Controlled Delivery, 114, 1-14. doi:10.1016/j.jconrel.2006.04.017

[9] Prashanth, K.V.H. and Tharanathan, R.N. (2007) Chitin/ chitosan: Modifications and their unlimited application potentialdan overview. Trends in Food Science \& Technology, 18, 117-131. doi:10.1016/j.tifs.2006.10.022

[10] Abdou, E.S., Nagy, K.S.A. and Elsabee, M.Z. (2008) Extraction and characterization of chitin and chitosan from local sources. Bioresource Technology, 99, 13591367. doi:10.1016/j.biortech.2007.01.051

[11] Chan, L.W., Jin, Y. and Heng, P.W.S. (2002) Cross-linking mechanisms of calcium and zinc in production of alginate microspheres. International Journal of Pharmaceutics, 242, 255-258. doi:10.1016/S0378-5173(02)00169-2

[12] Draget, K.I., Skjak-Braek, G. and Smidsrød, O. (1997) Alginate based new materials. International Journal of Biological Macromolecules, 21, 47-55. doi:10.1016/S0141-8130(97)00040-8

[13] Tønnesen, H.H. and Karlsen J. (2002) Alginate in drug delivery systems. Drug Development and Industrial Pharmacy, 28, 621-630. doi:10.1081/DDC-120003853

[14] Wittaya-Areekul, S., Kruenate, J. and Prahsarn, C. (2006) Preparation and in vitro evaluation of mucoadhesive properties of alginate/chitosan microparticles containing prednisolone. International Journal of Pharmaceutics, 312, 113-118. doi:10.1016/i.ijpharm.2006.01.003

[15] Rosina, C.R., Baroni, S. and Cavalcanti, O.A. (2004) Avaliação das propriedades de intumescimento e permeabilidade de filmes isolados de polimetacrilato contendo polissacarídeo da raiz de Lótus (Nelumbo nucifera). Brazilian Journal of Pharmaceutical Science, 40, 425431

[16] Lopes, M.C., Lobo, J.S.M. and Costa, P. (2005) Formas farmacêuticas de liberação modificada: Polímeros hidrofílicos. Brazilian Journal of Pharmaceutical Science, 41, 143-154.

[17] Cui, F., Yang, L., Jin, J., Piao, H.Z., Lin, W.H., Cun, D.M. (2007) Preparation and in vitro evaluation of $\mathrm{pH}$, timebased and enzyme-degradable pellets for colonic drug delivery. Drug Development and Industrial Pharmacy, 33, 999-1007. doi:10.1080/03639040601150393

[18] Costa, C.J.P. (2002) Avaliação in vitro da lioequivalência de formulações farmacêuticas. Brazilian Journal of Pharmaceutical Science, 38, 141-153.

[19] Kim, W.-T., Chung, H., Shin, Il-S., Yam, K.L. and Chung, D. (2008) Characterization of calcium alginate and chitosan-treated calcium alginate gel beads entrapping allyl isothiocyanate. Carbohydrate Polymers, 71, 566-573. doi:10.1016/j.carbpol.2007.06.028

[20] Meehan, E. (2006) Characterisation of hydroxypropylmethylcellulose phthalate (HPMCP) by GPC using a modified organic solvent. Analytica Chimica Acta, 557, 
2-6. doi:10.1016/j.aca.2005.06.017

[21] Rowe, R.C., Sheskey, P.P. and Owen, S.C. (2007) Handbook of pharmaceutical excipients. 5th Edition, Pharmaceutical Press, London.

[22] Yang, L. (2008) Biorelevant dissolution testing of colonspecific delivery systems activated by colonic microflora.
Journal of Controlled Release, 125, 77-86. doi:10.1016/j.jconrel.2007.10.026

[23] Lucinda-Silva, R.M., Monteiro, K.C.M., Carvalho, L.Q., Evangelista, R.C. (2006) Multiparticulate systems of pectin-chitosan: Study of swelling and drug release. Acta Farmceutica Bonaerense, 25, 538-543. 